\title{
Aspect under (and out of) control in Mandarin Chinese
}

Thomas Grano, University of Chicago

1 Introduction: Debate persists over whether Mandarin has a finite/nonfinite distinction. (See Huang 1982, 1989; Li 1985, 1990; C.C. Tang 1990; T.C. Tang 2000 for the affirmative view and Hu, Pan, and Xu 2001; Lin 2010 for the negative view.) Many phenomena have figured in this debate, including the distribution of embedded subjects, embedded modals, embedded aspect markers, and cross-clausal NPI licensing. This paper focuses on embedded aspect markers. I argue that recent work on the syntax and semantics of restructuring provides novel insight into the behavior of aspect marking in controlled complements, supporting the view in Huang 1982, 1989; Li 1985, 1990 that aspect under control is grammatical only when construed at the matrix level (contra Xu 1985-1986; $\mathrm{Hu}$ et al. 2001). The conclusion is that Mandarin has either a finite/nonfinite distinction or some kind of distinction responsible for a correlation between control and the distribution of aspect markers.

2 Background: Huang (1982, 1989); $\operatorname{Li}(1985,1990)$ observe that Mandarin embedded clauses come in two varieties: in one variety, exemplified in (1a), an overt subject and an overt aspect marker are both grammatical. In another variety, exemplified in (1b), an overt subject is ungrammatical (instead, an obligatory control relation obtains), and an overt aspect marker is ungrammatical as well.

$$
\begin{aligned}
& \text { a. ta shuo [ta lai-guo/-le]. } \\
& \text { 3SG say 3SG come-PRF } \\
& \text { 'He said he came.' }
\end{aligned}
$$
b. ta shefa $[(*$ ta) lai $(*$-guo/*-le $)]$. $3 \mathrm{SG}$ try $3 \mathrm{SG}$ come-PRF 'He tried to come.'

To explain this split, the authors propose that in (1b), the ungrammaticality of the subject and the ungrammaticality of the aspect marker both follow from the status of the embedded clause as nonfinite. In particular, on the assumption that aspect markers like -le and -guo project under AUX, nonfiniteness both precludes the projection of AUX and (given certain assumptions about how control works) requires a null PRO subject.

Faced with apparent counterexamples like (2) - where a subject is ungrammatical despite the grammaticality of an aspect marker - the authors argue that although the aspect marker is syntactically embedded, it is interpreted at the matrix level and thus not a true counterexample.

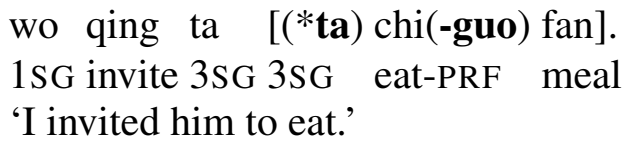

Xu (1985-1986); Hu et al. (2001), however, challenge this view based on the following argumentation. If the aspect marker in (2) is truly interpreted at the matrix level, then we should expect that it could be placed at the matrix level overtly with no change in meaning. As the minimal pair in (3) shows, however, this is not the case: when the aspect marker is at the matrix level as in (3a), the sentence is felicitous with the indicated parenthetical follow-up, whereas when the aspect marker is embedded as in $(3 \mathrm{~b})$, the parenthetical follow-up becomes contradictory.
a. wo qing-guo ta [chi fan], (keshi ta mei lai).
1SG invite-PRF 3SG eat meal but 3SG NEG.PRF come
'I invited him to eat, (but he did not come).'
b. wo qing ta [chi-guo fan], (\# keshi ta mei lai).
1SG invite 3SG eat-PRF meal but 3SG NEG.PRF come
'I invited him to eat, (\# but he did not come).'

(Xu 1985-1986:349)

Xu (1985-1986); Hu et al. (2001) do not, however, provide an explicit account of why the placement of the aspect marker covaries with interpretation in the way it does. In what follows, I provide such an account, and show that this account renders their criticism innocuous. 
3 Syntax: Aspect under control as restructuring Let us momentarily abstract away from the interpretational contrast in (3) (we will return to it in sect. 4), and focus for now on the syntactic fact to be captured: in some control sentences, the aspect marker can appear either "high" (4a) or "low" (4b).
a. wo qing-guo ta chi fan.
$1 \mathrm{SG}$ invite-PRF $3 \mathrm{SG}$ eat meal
'I invited him to eat.'
b. wo qing ta chi-guo fan.
$1 \mathrm{SG}$ invite $3 \mathrm{SG}$ eat-PRF meal
'I invited him to eat.'

Two observations lend preliminary support for a restructuring approach to this phenomenon. First, it is reminiscent of classic restructuring effects like Romance clitic climbing as exemplified in (5) (see e.g. Rizzi 1978 and much subsequent work). In both (4) and (5), there are two verbs in a tight embedding relationship and a morpheme that alternates between the higher and lower level.

$$
\begin{aligned}
& \text { a. Juan quiere ver[-]te. } \\
& \text { Juan wants see-2SG } \\
& \text { 'Juan wants to see you.' }
\end{aligned}
$$
b. Juan te quiere ver.
Juan 2SG wants see
'Juan wants to see you.'

SPANISH

Second, it is a general fact about Mandarin that suffixal aspect markers like -le and -guo cannot attach to preverbal functional heads. In the so-called $b a$ construction (see Huang, Li, and Li 2009:ch.5 and references therein) in (6), for example, -le may attach to the main verb but not to the preverbal functional head $b a$.

$$
\begin{aligned}
& \text { ta ba }\left\{*_{-} \text {le }\right\} \text { juzi bo }\{-l e\} \text { pi. } \\
& \text { 3SG BA orange peel-PRF skin } \\
& \text { 'He peeled the skin off the orange.' }
\end{aligned}
$$

My proposal incorporating these two observations is as follows. (4a) represents the gardenvariety (non-restructuring) case: Asp(ect) projects over VP, and the aspectual head -guo, because it is suffixal, lowers to attach to the highest verb qing 'invite'. (4b), on the other hand, instantiates FUNCTIONAL RESTRUCTURING (Wurmbrand 2001; Cinque 2006): the matrix verb is actually a functional head projecting over a monoclausal structure. Consequently, when -guo lowers, it passes over qing 'invite' (given the generalization that suffixal aspect markers cannot attach to functional heads in Mandarin), and instead attaches to $c h i$ 'eat' which in this construction is the main verb.

Without restructuring (4a):

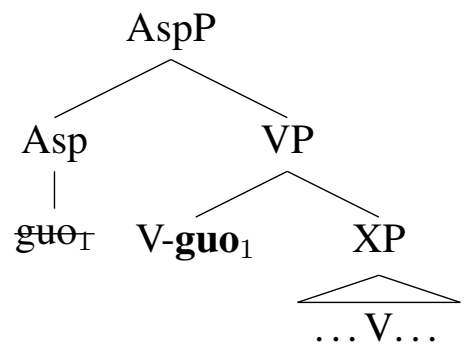

With restructuring $(4 b)$ :

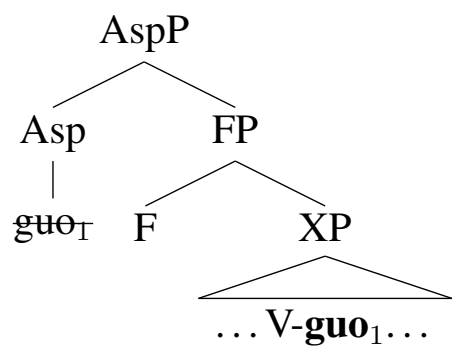

Independent support for this proposal comes from the the distribution of you - an allomorph of -le (conditioned by negation) which is not suffixal but remains high in its base position (7). In (8) we see that whereas in an affirmative sentence, -le may appear on the lower verb (which by hypothesis is due to restructuring) (8a), its negative counterpart does not admit embedded aspect (8b).

ta $\{$ mei-you $\}$ ba juzi $\left\{{ }^{*}\right.$ mei-you $\}$ bo pi.

3SG NEG-PRF BA orange NEG-PRF peel skin

'S/he has not peeled the orange.' 
a. wo bi ta lai-le.

1SG urge 3SG come-PRF

'I urged him to come.'

b. wo $\{$ mei-you $\}$ bi ta $\left\{{ }^{*}\right.$ mei-you $\}$ lai.

1SG NEG-PRF urge 3SG NEG-PRF come

'I didn't urge him to come.'

(Huang 1989:190)

We can rule out negation as a potential source for this asymmetry, for as (9) shows, there is in principle nothing wrong with negation under control.

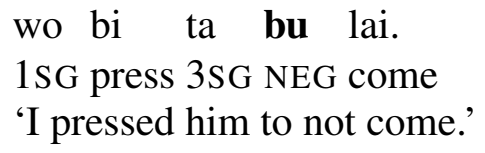

wo bi ta bu lai.

1SG press 3SG NEG come

'I pressed him to not come.'

Rather, the source of the asymmetry is the perfective allomorph you, and in particular, its non-affixal status. In the affirmative variant of the sentence (8a), functional restructuring results in -le attaching to the lower verb. In the negative variant (8b), on the other hand, the aspect marker is not affixal, and so regardless of whether restructuring takes place, it remains high in the structure:

\section{Positive sentence $\rightarrow$-le lowers to verb $\quad$ Negative sentence $\rightarrow$ you stays high}
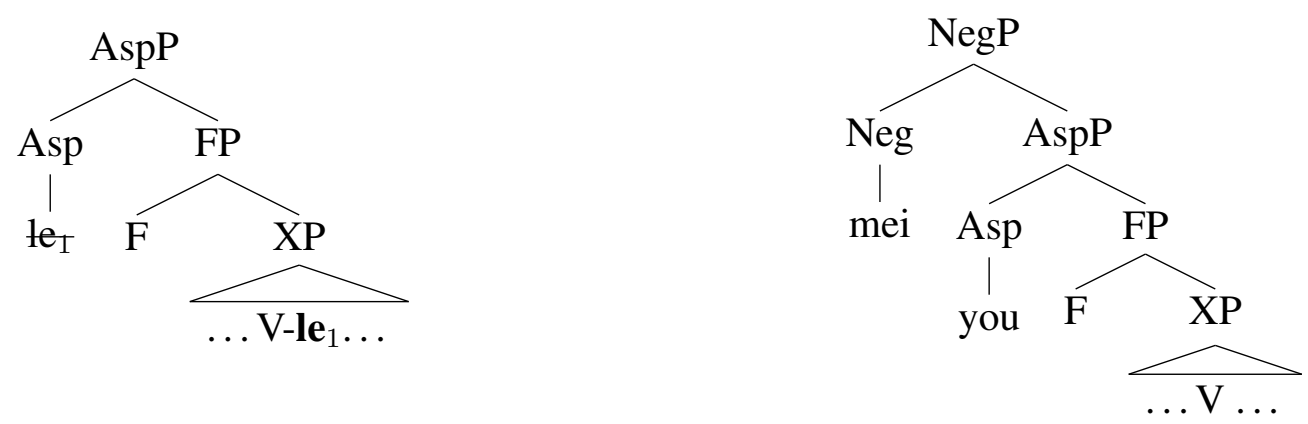

4 Semantics: From restructuring to actuality entailment We now return to the semantic puzzle: why does the high vs. low placement of the aspect marker have the interpretational effect seen in (10)?

a. wo qing-guo ta chi fan, (keshi ta mei lai).

1SG invite-PRF 3SG eat meal but 3SG NEG.PRF come

'I invited him to eat, (but he did not come).'

b. wo qing ta chi-guo fan, (\# keshi ta mei lai). $1 \mathrm{SG}$ invite $3 \mathrm{SG}$ eat-PRF meal but 3SG NEG.PRF come 'I invited him to eat (\# but he did not come).'

(Xu 1985-1986:349)

Preliminary evidence that, despite surface appearances, -guo in (10b) is not semantically embedded comes from the fact that it does not give rise to a relative past interpretation, which is what perfective aspect in Mandarin embedded clauses usually does (see e.g. Lin 2003) (11).

a. CONTEXT: Tomorrow I'm coming over to see you.

b. ni qianwan bu neng gaosu wo ge [wo kan guo ni]. 2SG definitely NEG can tell 1SG older-brother 1SG see PRF 2SG

'No matter what don't tell my older brother I saw you.'

c. guo signals: [EMBEDDED EVENT (SEEING) precedes MATRIX EVENT (TELLING)]

(10b) does not likewise signal [EMBEDDED EVENT (EATING) precedes MATRIX EVENT (INVITING)]. Rather, (10b) entails that the event associated with the embedded clause has been realized ('actuality entailment'). Hacquard (2008) argues that the combination of RESTRUCTURING and PERFECTIVE 
ASPECT is what gives rise to such actuality entailments, as exemplified by Italian in (12).

Gianni ha voluto parlare a Maria, (\# ma non lo ha fatto).

Gianni want-PST-PFV talk to Maria but NEG it do-PST-PFV

'Gianni wanted to talk to Maria, \#but he didn't do it.'

ITALIAN

For Hacquard, actuality entailments arise when Asp takes wide scope over the matrix verb and binds the event variable of the embedded verb (13a) (Cf. (13b): in the absence of restructuring, the matrix verb has its own event argument, and the event argument of the embedded verb is bound locally under the scope of the matrix verb.)

a. $\quad \mathrm{T} \mathrm{Asp}_{1} \mathrm{~V}$ VP( $\left(\mathrm{e}_{1}\right)$

RESTRUCTURING: ACTUALITY ENTAILMENT

b. $\quad \mathrm{T} \mathrm{Asp}_{1} \mathrm{~V}\left(\mathrm{e}_{1}\right) \mathrm{T} \mathrm{Asp}_{2} \mathrm{VP}\left(\mathrm{e}_{2}\right)$

NON-RESTRUCTURING: NO ACTUALITY ENTAILMENT

Adopting this approach for Mandarin yields the following structures for (10a) and (10b) respectively:

$$
\begin{array}{ll}
\text { a. } & {\left[A s p P\left[{ }_{A s p} \mathrm{guo}_{1}\right]\left[{ }_{V P} \mathrm{~V}\left(\mathrm{e}_{1}\right)\left[X P \ldots \emptyset_{A s p 2} \mathrm{~V}\left(\mathrm{e}_{2}\right) \ldots\right]\right]\right]} \\
\text { b. } & {\left[{ }_{A s p P}\left[{ }_{A s p} \mathrm{guo}_{1}\right]\left[{ }_{F P} \mathrm{~F}\left[X P \ldots \mathrm{V}\left(\mathrm{e}_{1}\right) \ldots\right]\right]\right]}
\end{array}
$$

In $(14 \mathrm{a})(=(10 \mathrm{a}))$, no restructuring takes places, and hence there is no actuality entailment. In (14b) $(=(10 \mathrm{~b}))$, on the other hand, restructuring takes places, and an actuality entailment obtains. The upshot is that Hacquard's approach to actuality entailments provides an explanation for the interpretational contrast between (10a) and (10b), in a way consistent with the restructuring analysis advocated above. 5 Conclusion: The central conclusion is that Mandarin aspect under control - when grammatical at all — is uniformly interpreted at the matrix level, as argued by Huang (1982, 1989); Li (1985, 1990); contra Xu (1985-1986); Hu et al. (2001). For Huang and Li, this finding means that Mandarin has a finite/nonfinite distinction. Recent crosslinguistic work on control by Landau (2004), however, suggests that the finite/nonfinite distinction may be too crude for capturing the distribution of PRO, and that instead, PRO is sensitive to [Tense] and [Agr] values on both I and C of the embedded clause. If such an approach extends to Mandarin, then the task for future research is to investigate how Mandarin [Tense] and [Agr] features conspire both to license PRO and to restrict the distribution of Aspect.

\section{References}

Cinque, Guglielmo. 2006. Restructuring and functional heads. Oxford: Oxford University Press.

Hacquard, Valentine. 2008. Restructuring and implicative properties of volere. In Proceedings of SuB12, ed. Atle Grønn. Oslo: ILOS.

Hu, Jianhua, Haihua Pan, and Liejiong Xu. 2001. Is there a finite vs. nonfinite distinction in Chinese? Linguistics 39:1117-1148.

Huang, C.-T. James. 1982. Logical relations in Chinese and the theory of grammar. Ph.D. Dissertation, MIT.

Huang, C.-T. James. 1989. Pro-drop in Chinese: a generalized control theory. In The null subject parameter, ed. Osvaldo Jaeggli and Kenneth Safir, 185-214. Dordrecht: Kluwer.

Huang, C.-T. James, Y.-H. Audrey Li, and Yafei Li. 2009. The syntax of Chinese. Cambridge: Cambridge University Press. Landau, Idan. 2004. The scale of finiteness and the calculus of control. Natural Language \& Linguistic Theory 22:811-877.

Li, Tiegen. 1999. The study of tense in Modern Chinese. Shenyang: Liaoning University Press.

Li, Yen-Hui Audrey. 1985. Abstract case in Chinese. Ph.D. Dissertation, USC.

Li, Yen-Hui Audrey. 1990. Order and constituency in Mandarin Chinese. Dordrecht: Kluwer Academic Publishers.

Lin, Jo-Wang. 2003. Temporal reference in Mandarin Chinese. Journal of East Asian Linguistics 12:259-311.

Lin, Jo-Wang. 2010. A tenseless analysis of Mandarin Chinese revisited: A response to Sybesma 2007. Linguistic Inquiry 41:305-329.

Rizzi, Luigi. 1978. A restructuring rule in Italian syntax. In Recent transformational studies in European languages, ed. Samuel J. Keyser, 113-158. Cambridge: MIT Press.

Tang, Chih-Chen Jane. 1990. Chinese phrase structure and the extended X'-theory. Ph.D. Dissertation, Cornell University.

Tang, Ting-Chi. 2000. Finite and nonfinite clauses in Chinese. Language and Linguistics 1:191-214.

Wurmbrand, Susi. 2001. Infinitives: Restructuring and clause structure. Berlin: Mouton de Gruyter.

Xu, Liejiong. 1985-1986. Towards a lexical-thematic theory of control. Linguistic Review 5:345-376. 